David Ruttens ${ }^{1}$, Stijn E. Verleden ${ }^{1}$, Pieter C. Goeminne ${ }^{1}$, Katrien Poels ${ }^{2}$, Elly Vandermeulen ${ }^{1}$, Lode Godderis ${ }^{2}$, Dirk E. Van Raemdonck ${ }^{1}$, Bart M. Vanaudenaerde ${ }^{1}$, Jeroen Vanoirbeek ${ }^{2}$, Robin Vos ${ }^{1}$ and Geert M. Verleden ${ }^{1}$ ${ }^{1}$ Lung Transplant Unit, Laboratory of Pneumology, Katholieke Universiteit Leuven, University Hospital Leuven, Leuven, and ${ }^{2}$ Laboratory for Occupational and Environmental Hygiene, Center for Environment and Health, Katholieke Universiteit Leuven, Leuven, Belgium.

Correspondence: G.M. Verleden, Lung Transplant Unit, Laboratory of Pneumology, Katholieke Universiteit Leuven, University Hospital Leuven, 49 Herestraat, B-3000 Leuven, Belgium. E-mail: geert.verleden@uzleuven.be

Received: June 282013 | Accepted after revision: Aug 142013 | First published online: Aug 292013

Support statement: Funding of the research group includes the GlaxoSmithKline (Wavre, Belgium) Chair in Respiratory Pharmacology at the Katholieke Universiteit Leuven (Leuven, Belgium), and grants from the Research Foundation Flanders (Brussels, Belgium) (G.0723.10, G.0679.12 and G.0705.12) and the Katholieke Universiteit Leuven (OT10/050).

Conflict of interest: None declared.

\title{
References
}

1 Glanville AR, Estenne M. Indications, patient selection and timing of referral for lung transplantation. Eur Respir J 2003; 22: 845-852.

2 van der Heide F, Dijkstra G, Porte RJ, et al. Smoking behavior in liver transplant recipients. Liver Transpl 2009; 15: 648-655.

3 Corbett C, Armstrong MJ, Neuberger J. Tobacco smoking and solid organ transplantation. Transplantation 2012; 94: 979-987.

Botha P, Peaston R, White K, et al. Smoking after cardiac transplantation. Am J Transplant 2008; 8: 866-871. Vos R, De Vusser K, Schaevers V, et al. Smoking resumption after lung transplantation: a sobering truth. Eur Respir J 2010; 35: 1411-1413.

6 Herrero JI, Pardo F, D’Avola D, et al. Risk factors of lung, head and neck, esophageal, and kidney and urinary tract carcinomas after liver transplantation: the effect of smoking withdrawal. Liver Transpl 2011; 17: 402-408.

7 Orens JB, Estenne M, Arcasoy S, et al. Risk factors for cancer in renal transplant recipients. Transplantation 1999; 68: $1859-1864$

8 Sampaio MS, Cho YW, Qazi Y, et al. Post-transplant malignancies in solid organ adult recipients: an analysis of the US National Transplant Database. Transplantation 2012; 94: 990-998.

9 Warnier MJ, van Riet EE, Rutten FH, et al. Smoking cessation strategies in patients with COPD. Eur Respir J 2013; 41: 727-734.

\section{Can diaphragm pacing improve gas exchange? Insights from quadriplegic patients}

\author{
To the Editor:
}

Diaphragm pacing, as obtained by phrenic nerve stimulation through implanted electrodes, is a valid alternative to positive pressure mechanical ventilation (PPV) in patients with high spinal cord injuries [1]. Diaphragm pacing allows such patients to be weaned from PPV, but, to date, the respective effects of diaphragm pacing and PPV on gas exchange have not been compared. PPV is known to reduce ventilation in the lung bases [2]. By contrast, diaphragm pacing, like spontaneous breathing, should direct a larger proportion of the inspired volume to the lung bases. This should improve ventilation/perfusion matching. If this is the case, diaphragm pacing could be of interest as an adjunct to PPV in patients with lung injury. Indeed, in this setting, preserving diaphragmatic activity during mechanical ventilation can improve arterial oxygenation [3]. However, this can be difficult to achieve from a comfort point of view. In a proof-ofconcept perspective, we compared blood gases and energy expenditure during PPV and diaphragm pacing in 10 quadriplegics.

10 consecutive, stable and well-nourished tracheotomised quadriplegic patients were studied (six males, aged 15-46 years, mean $\pm \mathrm{SD}$ body mass index $21.9 \pm 4.0 \mathrm{~kg} \cdot \mathrm{m}^{-2}$ ). All had a phrenic nerve stimulator (Atrostim; Atrotech, Tampere, Finland) implanted at least 6 months earlier and were considered fully reconditioned. They were studied during planned routine visits, after approval of the ethics committee of the French Learned Society for Intensive Care Medicine. All patients gave their informed consent. Measurements were performed at least $3 \mathrm{~h}$ after a meal, with the tracheal cuff inflated. Oxygen consumption 
$\left(V^{\prime} \mathrm{O}_{2}\right)$, carbon dioxide production $\left(V^{\prime} \mathrm{CO}_{2}\right)$ and respiratory quotient were determined from oxygen and carbon dioxide measurements in inspired and expired gases (Deltatrac Metabolic Monitor; Datex, Helsinki, Finland). Resting energy expenditure was calculated according to the Ben-Porat formula [4]. Arterial blood gases were analysed extemporaneously (Omni9; AVL, Shaffhausen, Switzerland). Tidal volume $(V T)$, respiratory frequency $(f \mathrm{R})$ and minute ventilation $\left(V^{\prime} \mathrm{E}\right)$ were measured using a portable differential pressure spirometer (Spiro+; Saime, Savigny-le-temple, France). In each patient, a routine control of the stimulator was first performed. The patient was then switched to PPV and the home ventilator settings were adjusted to provide a fR and $V \mathrm{~T}$ as close as possible to that measured during diaphragm pacing. The metabolic measurements started 15-30 min later. They were repeated every $3 \mathrm{~min}$, until metabolic steady state was achieved $(<5 \%$ change in $V^{\prime} \mathrm{O}_{2}, V^{\prime} \mathrm{CO}_{2}$ and respiratory quotient). The patient was then switched back to diaphragm pacing and the measurements repeated according to the same sequence and criteria. The patients were studied in a semireclined posture in their bed, with no posture change between phrenic pacing and PPV. The instrument dead space was kept identical. Heart rate, blood pressure and body temperature were monitored. It is noteworthy that no inspiratory neck muscle use was observed during diaphragm pacing or PPV. The entire dataset passed the Shapiro-Wilk test for normality and the results are, therefore, presented as mean $\pm \mathrm{SD}$. Comparisons were performed using the paired t-test. Differences were considered significant for $\mathrm{p}<0.05$.

The breathing patterns during diaphragm pacing and PPV were similar (diaphragm pacing: VT $798 \pm 274 \mathrm{~mL}$, $f R 13.6 \pm 2.3$ breaths $\cdot \mathrm{min}^{-1}, V^{\prime} \mathrm{E} 10.5 \pm 2.8 \mathrm{~L}$; PPV: $V \mathrm{~T} 710 \pm 174 \mathrm{~mL}, f \mathrm{R} 14.6 \pm 2.1$ breaths $\left.\cdot \mathrm{min}^{-1}, V^{\prime} \mathrm{E} 10.3 \pm 2.8 \mathrm{~L}\right)$. No difference in blood pressure, heart rate and temperature was observed. During diaphragm pacing, arterial oxygen tension $\left(\mathrm{PaO}_{2}\right)$ increased, but without reaching statistical significance (table 1); however, there was a dramatic fall in the alveolar-arterial oxygen tension difference $\left(P \mathrm{~A}-\mathrm{aO}{ }_{2}\right)$ (diaphragm pacing: $11.4 \pm 11.6 \mathrm{mmHg}$; PPV: $28.9 \pm 14.1 \mathrm{mmHg} ; \mathrm{p}=0.005)$. Similarly, physiological dead space (Bohr formula) was $0.48 \pm 0.10$ under PPV and $0.38 \pm 0.11$ under diaphragm pacing $(\mathrm{p}=0.023)$. Diaphragm pacing was associated with an immediate rise in $V^{\prime} \mathrm{O}_{2}\left(\mathrm{PPV}: 183.6 \pm 27.4 \mathrm{~mL} \cdot \mathrm{min}^{-1}\right.$; diaphragm pacing: $\left.207.8 \pm 28.9 \mathrm{~mL} \cdot \mathrm{min}^{-1} ;+14.2 \% ; \mathrm{p}<0.0001\right) \quad($ table 1$)$ and in $V^{\prime} \mathrm{CO}_{2} \quad\left(\mathrm{PPV}: 154.7 \pm 24.4 \mathrm{~mL} \cdot \mathrm{min}^{-1}\right.$; diaphragm pacing: $173.6 \pm 25.6 \mathrm{~mL} \cdot \mathrm{min}^{-1} ;+12.7 \%$; $\left.<<0.0001\right)$ without a change in respiratory quotient (PPV: $0.84 \pm 0.04$; diaphragm pacing: $0.85 \pm 0.02$ ). In spite of the rise in $V^{\prime} \mathrm{CO}_{2}$, arterial carbon dioxide tension $\left(\mathrm{PaCO}_{2}\right)$ during diaphragm pacing was not higher than during PPV, probably in line with the reduced dead space. Resting energy expenditure was $3552.0 \pm 536.6 \mathrm{~kJ} \cdot \mathrm{day}^{-1}$ during PPV and $4051.9 \pm 562.3 \mathrm{~kJ} \cdot \mathrm{day}^{-1}$ during pacing $(+21 \%$; $\mathrm{p}<0.0001)$.

From our observations, it appears that for a given level of ventilation, diaphragm pacing improves gas exchange relative to PPV. This conclusion might not seem obvious in view of the nonsignificant rise in $\mathrm{PaO}_{2}$ and the lack of change in $\mathrm{PaCO}_{2}$, but it is nevertheless clearly warranted if one looks beyond these variables.

\begin{tabular}{|c|c|c|c|}
\hline & PPV & Diaphragm pacing & p-value \\
\hline \multicolumn{4}{|l|}{ Breathing pattern } \\
\hline $\mathrm{V} T \mathrm{~mL}$ & $710 \pm 174$ & $798 \pm 274$ & 0.195 \\
\hline$f R$ breaths $\cdot \min ^{-1}$ & $14.6 \pm 2.1$ & $13.6 \pm 2.3$ & 0.372 \\
\hline$V^{\prime} E L \cdot \min ^{-1}$ & $10.3 \pm 2.8$ & $10.5 \pm 2.8$ & 0.826 \\
\hline \multicolumn{4}{|l|}{ Gas exchange } \\
\hline $\mathrm{pH}$ & $7.50 \pm 0.04$ & $7.48 \pm 0.04$ & 0.236 \\
\hline $\mathrm{PaO}_{2} \mathrm{mmHg}$ & $93.1 \pm 17.1$ & $105.5 \pm 15.5$ & 0.061 \\
\hline $\mathrm{PaCO}_{2} \mathrm{mmHg}$ & $24.0 \pm 5.5$ & $26.3 \pm 7.0$ & 0.433 \\
\hline $\mathrm{PA}-\mathrm{aO}_{2} \mathrm{mmHg}$ & $28.9 \pm 14.1$ & $11.4 \pm 11.6$ & 0.005 \\
\hline$V_{D} / V_{T}$ & $0.48 \pm 0.10$ & $0.38 \pm 0.11$ & 0.023 \\
\hline \multicolumn{4}{|l|}{ Metabolism } \\
\hline$V^{\prime} \mathrm{O}_{2} \mathrm{~mL} \cdot \mathrm{min}^{-1}$ & $183.6 \pm 27.4$ & $207.8 \pm 28.9$ & $<0.0001$ \\
\hline$V^{\prime} \mathrm{CO}_{2} \mathrm{~mL} \cdot \mathrm{min}^{-1}$ & $154.7 \pm 24.4$ & $173.6 \pm 25.6$ & $<0.0001$ \\
\hline $\mathrm{RQ}$ & $0.84 \pm 0.04$ & $0.85 \pm 0.02$ & 0.753 \\
\hline REE kJ. day ${ }^{-1}$ & $3552.00 \pm 536.6$ & $4051.94 \pm 562.27$ & $<0.0001$ \\
\hline
\end{tabular}

Data are presented as mean $\pm S D$, unless otherwise stated. $V_{T}$ : tidal volume; fR: respiratory frequency; $V^{\prime} E$ : minute ventilation; $\mathrm{PaO}_{2}$ : arterial oxygen tension; $\mathrm{PaCO}_{2}$ : arterial carbon dioxide tension; $\mathrm{PA}-\mathrm{aO} \mathrm{O}_{2}$ : alveolararterial oxygen tension difference; $\mathrm{VD} / \mathrm{VT}$ : physiological dead space (Bohr formula); $\mathrm{V}^{\prime} \mathrm{O}_{2}$ : oxygen consumption; $V^{\prime} \mathrm{CO}_{2}$ : carbon dioxide production; $\mathrm{RQ}$ : respiratory quotient; REE: resting energy expenditure. 
Regarding oxygenation, our most salient finding is the markedly reduced $\mathrm{PA}_{\mathrm{a}-\mathrm{O}}$ during diaphragm pacing. In the absence of diffusion abnormalities, this points to a reduced shunt effect that could result from diaphragm pacing directing a greater proportion of the inspired volume, than PPV, to the lower regions of the lungs, as occurs in spontaneous breathing [2]. Consistent with this hypothesis, Di MARCO et al. [5] observed better gas exchange in anaesthetised dogs during diaphragm pacing as compared with intercostal pacing, at similar levels of ventilation. Diaphragm pacing could also have reopened collapsed or nearcollapsed lung areas, which are frequently observed in quadriplegic patients.

Regarding carbon dioxide elimination, we observed a $12 \%$ rise in $V^{\prime} \mathrm{CO}_{2}$ during diaphragm pacing. Because $V^{\prime} \mathrm{E}$ was identical during PPV and diaphragm pacing, this should have translated into a rise in $\mathrm{PaCO}_{2}$. This did not occur, hence the more efficient carbon dioxide elimination during diaphragm pacing in line with the documented reduction in dead space (table 1). The $12 \%$ rise in $V^{\prime} \mathrm{CO}_{2}$ during diaphragm pacing was the consequence of a $15 \%$ rise in $V^{\prime} \mathrm{O}_{2}$. In the absence of major stress and of an obvious carbon dioxide storage issue (constant respiratory quotient), this is likely to represent the addition of the diaphragm pacing-related oxygen cost of breathing to basal metabolism. Yet data in the literature put respiratory $V^{\prime} \mathrm{O}_{2}$ closer to $5 \%$ of total $V^{\prime} \mathrm{O}_{2}$ in quadriplegics [6]. As observed in most quadriplegics [7], our patients were over-ventilated during diaphragm pacing and PPV (table 1). Calculating what would have been a "normocapnic $V^{\prime} \mathrm{O}_{2}$ " reduced our diaphragm $V^{\prime} \mathrm{O}_{2}$ values by $30 \%$. In addition, diaphragm reconditioning by low-frequency stimulation may have shifted fibre composition towards highly oxidative type I fibres [8]. Whatever the mechanisms involved, the diaphragm pacing-related resting energy expenditure increase documented here should be taken into account in the nutritional management of these patients.

Beyond its clinical value in quadriplegics, diaphragm pacing has potential physiological advantages. It can improve cardiac performance through an increased abdominothoracic pressure gradient [9]. Preliminary data indicate that it could protect the diaphragm against ventilator-induced injury [10, 11]. The present observations suggest that it can provide better gas exchange than PPV. We submit that these observations are a reasonable rationale to evaluate the effects of diaphragm pacing as an adjunct to PPV on gas exchange in mechanically ventilated patients suffering from acute lung disease. Animal data should be obtained first, keeping in mind that emerging minimally invasive techniques for temporary diaphragm pacing should soon provide clinical feasibility [12]. We anticipate that effects similar to those described when preserving spontaneous breathing during mechanical ventilation in patients with acute lung injury [3] should be observed. We also anticipate that this approach should make the equilibrium between preserved diaphragm activity and patient comfort easier to achieve.

O @ERSpublications

Diaphragm pacing reduces alveolo-arterial gradient and dead space compared with positive pressure ventilation in humans http://ow.ly/pPC25

Jésus Gonzalez-Bermejo ${ }^{1,2}$, Capucine Morélot-Panzini ${ }^{1,2}$, Marjolaine Georges ${ }^{1,2}$, Alexandre Demoule ${ }^{2,3}$ and Thomas Similowski ${ }^{1,2}$

${ }^{1}$ Université Paris 6 Pierre et Marie Curie, ER10, Paris, ${ }^{2}$ Assistance Publique - Hôpitaux de Paris, Groupe Hospitalier Pitié-Salpêtrière Charles Foix, Service de Pneumologie et Réanimation Médicale, Paris, and ${ }^{3}$ INSERM UMRS 974, Paris, France.

Correspondence: T. Similowski, Service de Pneumologie et Réanimation Médicale, Groupe Hospitalier Pitié-Salpêtrière Charles Foix, 47-83 Bd de l'Hôpital, 75651 Paris Cedex 13, France. E-mail: thomas.similowski@psl.ap-hop-paris.fr

Received: July 252013 | Accepted after revision: Aug 192013 | First published online: Sept 132013

Support statement: This study is ancillary to a project supported by grant DRC98075 from the Programme Hospitalier de Recherche Clinique National of the French Ministry of Health. It was also supported by the programme "Investissements d'avenir" ANR-10-IAIHU-06 of the French State.

Conflict of interest: Disclosures can be found alongside the online version of this article at www.erj.ersjournals.com

\section{References}

1 Romero FJ, Gambarrutta C, Garcia-Forcada A, et al. Long-term evaluation of phrenic nerve pacing for respiratory failure due to high cervical spinal cord injury. Spinal Cord 2012; 50: 895-898.

2 Bynum LJ, Wilson JE 3rd., Pierce AK. Comparison of spontaneous and positive-pressure breathing in supine normal subjects. J Appl Physiol 1976; 41: 341-347.

3 Putensen C, Mutz NJ, Putensen-Himmer G, et al. Spontaneous breathing during ventilatory support improves ventilation-perfusion distributions in patients with acute respiratory distress syndrome. Am J Respir Crit Care Med 1999; 159: 1241-1248.

4 Ben-Porat M, Sideman S, Bursztein S. Energy metabolism rate equation for fasting and postabsorptive subjects. Am J Physiol 1983; 244: R764-R769. 
DiMarco AF, Connors AF Jr, Kowalski KE. Gas exchange during separate diaphragm and intercostal muscle breathing. J Appl Physiol 2004; 96: 2120-2124.

6 Manning H, McCool FD, Scharf SM, et al. Oxygen cost of resistive-loaded breathing in quadriplegia. J Appl Physiol 1992; 73: 825-831.

7 Watt JW, Silva P. Respiratory alkalosis and associated electrolytes in long-term ventilator dependent persons with tetraplegia. Spinal Cord 2001; 39: 557-563.

8 Marzocchi M, Brouillette RT, Klemka-Walden LM, et al. Effects of continuous low-frequency pacing on immature canine diaphragm. J Appl Physiol 1990; 69: 892-898.

9 Roos M, Kobza R, Jamshidi P, et al. Improved cardiac performance through pacing-induced diaphragmatic stimulation: a novel electrophysiological approach in heart failure management? Europace 2009; 11: $191-199$.

10 Masmoudi H, Coirault C, Demoule A, et al. Can phrenic stimulation protect the diaphragm from mechanical ventilation-induced damage? Eur Respir J 2013; 42: 280-283.

11 Gayan-Ramirez G. Ventilator-induced diaphragm dysfunction: time for (contr)action! Eur Respir J 2013; 42: $12-15$.

12 Hoffer JA, Tran B, Tang J, et al. Diaphragm pacing with endovascular electrodes. In: Mandl T, Martinek J, Manfred B, et al. eds. Proceedings of the 10th Vienna International Workshop on Functional Electrical Stimulation and the 15th IFESS Annual Conference, 2010, guest Neuromodulation 2010: The Way Ahead. Vienna, Center for Medical Physics and Biomedical Engineering Medical University of Vienna, 2010; 41-42. Available from: http://ifess.org/ proceedings/IFESS2010/IFESS2010.pdf

Eur Respir J 2014; 43: 303-306 | DOI: 10.1183/09031936.00127713 | Copyright @ERS 2014 